pharmacy course, and a number of short courses on glass-working, instrument technology, etc., and an ordinary national certificate course in metallurgy.

The College is also recognized for the award of the higher national certificate in chemical engineering.

The Domestic Studies Department covers a wide range of examination courses leading to the award of the City and Guilds or Union of Lancashire and Cheshire Institutes' certificates in cookery, dressmaking, needlework, tailoring, upholstery, and the Educational Development Association certificates in basketry. Bakery courses were started in September in preparation for the City and Guilds intermediate examination in bread-making and flour confectionery. Catering courses include the catering trades basic training course (City and Guilds), cookery for hotels and restaurants (City and Guilds), and catering for non-residential licensed houses.

The total accommodation in the College, apart from the administrative offices, consists of forty-two classrooms, five lecture theatres, sixteen laboratories, three commerce rooms, geography room, three domestic study rooms, three craft rooms, ten workshops, a bakery and a butchery.

The first principal of the College, Mr. C. V. Vinten Fenton, has a staff of forty-two full-time and two hundred part-time teachers. Mr. Fenton, before going to Birkenhead, was the first principal of the Peterborough College; there he was responsible for organizing technical education and saw the completion of the first phase of the new technical college built in that city.

\section{ASLIB SCOTTISH BRANCH}

\section{ANNUAL MEETING}

$\mathrm{T}$ HE annual general meeting and one-day conference of the Scottish Branch of Aslib (Association of Special Libraries and Information Bureaux) was held in the Mitchell Library, Glasgow, on February 11. The first paper of the morning was given by Dr. B. J. A. Bard, industrial manager of the National Research Development Corporation. He spoke of the work of the Corporation since its inception in 1950 and described its function as the development and exploitation, in the public interest, of inventions resulting from research carried out by government departments and other public bodies, and private inventions where they are of primary importance to the public interest. Dr. Bard outlined the organization of the Corporation, described how inventions are exploited and developed, and gave a general description of some of the projects in hand.

Following this paper, there was a symposium on the treatment and circulation of periodicals. The first speaker was Miss E. Handlen, librarian of the Department of the Secretary of State for Scotland. She said that, whatever the scope of a library, two demands are common to all: users want to see articles as soon as they are published, and they want to go to the library and find articles to help with a problem. Dealing with up to two thousand titles received by the Department of the Secretary of State for Scotland, these are sorted and the date of arrival recorded, and they are then circulated according to simple circulation slips made up so that the most senior officers have priority.

In this way, periodicals are circulated around seven hundred chosen users, although this figure should be trebled because officers on the lists show important articles to their juniors. All, or nearly all, periodicals are brought back to the Library, preferably before a new issue arrives. To help in this circulation, the Library has specially printed cards arranged alphabetically in a tumble-card cabinet with spaces on the face for the date entries, and other more permanent information on the back (the circulation, start of run, binding, etc.). This permits 'flagging' any item which needs special attention. One man can handle the work. It sometimes happens that a periodical circulated to medical men may contain an article of value to, say, a sanitary engineer. The supplementary service for these fits into the general circulation scheme; the first name on circulation lists is that of the librarian, and Miss Handlen includes the odd articles in the accessions lists, so that officers who have missed circulations can borrow. Such cases amount to less than ten in one month. There may be about the same number of important articles meriting inclusion in the subject card-index.

Miss Handlen favours duplication of purchase in the case of periodicals of ephemeral interest, since this permits retention of one master set and cutting of the other copies, thus saving time and labour in copying. She emphasized that circulation of periodicals is necessary where there are 700 users and 29,000 issues, and that display and retention in the library would be quite impracticable. Even in a smaller library, the display system would lead to loans, and loans are not as quick as circulations and are more costly in staff time. Full indexing of articles is not possible, and Miss Handlen said that full indexing often seems to defeat its own ends, being extremely cumbersome and costly for small results. Finally, she asked if there is not a danger of a librarian coming too much between the user and the holdings. She felt that librarianship is in danger of becoming an esoteric clerical job if too much is attempted in the way of carding every reference. Miss Handlen said that she would rather contribute $£ 25$ a year to an abstracting journal to help it become more efficient and up to date in publication than pay $£ 500$ to an extra assistant to anticipate the abstracts.

The second speaker in the symposium was Mr. A. Liddle, librarian to the firm of Babcock and Wilcox, Ltd., who described the controlled circulation of a hundred and forty periodical titles to approximately a hundred and twenty readers, most of whom are within the firm's research station. The circulation slips affixed to the periodical have columns for name, department, see pages, date sent, returned and initials. A section is provided for readers to note that they wish pages to be abstracted and indexed in the central file. Normally, periodicals are displayed for seven days so that anyone can add their name to the circulation list, or delete it if it is already there and that issue is not of further interest. Mr. Liddle thought that the time necessary for recording is justifiable by results and described the visible card system used. To help in the service of getting information to users as quickly as possible, the periodicals are first scanned and items of current interest are abstracted and produced in the form of a weekly bulletin.

The third speaker in the symposium was Mr. J. R.K. Pirie, librarian of the Mechanical Engineering Research Laboratory, East Kilbride, of the Department of Scientific and Industrial Research. He outlined the difficulty of circulating three hundred and 
fifty periodicals to staff housed in several buildings, one set being more than four miles from the main central library. The staff have been asked which perfodicals they wish to see, and only nineteen were asked for by more than eight readers; circulation lists were then drawn up. Periodicals are normally displayed for seven days, allowing members of staff to scan and delete their names from the lists if there is nothing of interest. Circulation priority is arranged into the categories of 'urgent', 'personal' and 'departmental'. The system of recording is that described by its designer, Miss Ruth Jacobs (then of the Department of Scientific and Industrial Research), in the Journal of Documentation, 6 (4), 213 (1950). Names of borrowers are grouped, so that periodicals are returned to the library after every three or four names for checking.

The afternoon session was devoted to a paper by Mr. F. W. Gravell, librarian of the Patent Office. He spoke of the purpose and process of patenting an invention, and described the scope and work of the Patent Office Library. The full text of the papers by Dr. Bard and Mr. Gravell will be published in Aslib Proceedings in due course. Margaret Spende

\section{LINEN INDUSTRY RESEARCH ASSOCIATION}

A $\mathrm{T}$ the thirty-fifth annual general meeting of A the linen Industry Research Association on December 17, 1954, both the chairman, Mr. H. B. McCance, and Mr. N. V. Cooke, in proposing and seconding the motion to adopt the report of the council and the accounts, stressed the importance of making sure that the industry gets the best value for the expenditure of $£ 70,000$ a year on research. Mr. MeCance urged that research should be concentrated on a few well-defined objectives of such importance that the industry would at once provide the whole of the money required if the government contribution were withdrawn. Mr. Cooke emphasized the importance of securing staff of outstanding ability and especially with imagination, at least some of whom should come from outside the industry. This point was welcomed by the director of research, Dr. A. J. Turner, who also stressed the value of those of the staff who had been appointed for their technical knowledge and experience. Most of the present staff had come to the Association with no previous knowledge of textiles; but the Association is still trying to obtain one or two more senior men of the type Mr. Cooke considers necessary.

In reviewing the year's work, Dr. Turner said that we are in the throes of a new industrial revolution arising out of the modern advances in physics and chemistry. In so far as the linen industry is still a craft industry, a great struggle is involved in trying to prevent it from shrinking further in competition with the man-made fibres. It will be necessary to attempt to process specially selected man-made fibres on flax machinery to obtain special effects and novelties. The linen industry of the future can be transformed so as to include the man-made staple fibres, and unique blends of such fibres with one another or with flax can be made into new and readily saleable cloths. Little work is at present being done by the Association on flax production. In the spinning departments the most interesting fundamental research is that on yarn irregularity.
Dr. Turner also referred to the value of starch ethers and cellulose ethers as sizing agents for linen yarns ; but the advances in polymer chemistry have been most keenly felt in the chemistry department, particularly as regards special proofing finishes, and the possibilities are far from being exhausted.

The report of the Council of the Linen Industry Research Association for the year ended September $30,1954^{*}$, records a slight fall in membership, from 285 to 281 , and regrets also the decision by the Government to terminate, on economic grounds, the Home Flax Production Scheme. There has also been a large contraction in the flax acreage in Northern Ireland, where tank retting has almost ceased, and in consequence research work on tank retting problems has been suspended. Research work on spinning has resulted in mechanical modifications for improving the operation of drawing frames and in recommendations for improving the control of yarn quality and the efficiency. A new system has been developed for controlling the levelness of drafting, and the study of the strength relation of yarns and cloths has enabled the necessary yarn strengths to be predicted when making cloths of certain specification. A new test has been devised for measuring the absorb. ency of cloth during the first few seconds of contact with a wet surface, and promising results have been obtained in factory trials with some new sizing materials. A prototype production model of the new spool winder, which makes packages suitable for overend unwinding, is now being built; much attention has been given to proofing linen fabrics, and improvements have been made in waterproofing flax canvases with pigmented drying oils and with oils and waxes applied from emulsions.

* Linen Industry Research Association. Report of the Council, 1954. Pp. 20. (Belfast : Linen Industry Research Association, 1954.)

\section{APPARENT HETEROGENEITY OF DEOXYRIBONUCLEIC ACID : SEDIMENTATION EXPERIMENTS AT LOW CONCENTRATIONS}

By DR. K. V. SHOOTER and Prof. J. A. V. BUTLER

Chester Beatty Research Institute, Institute of Cancer Research : Royal Cancer Hospital, Fulham Road, London, S.W.3

CEDIMENTATION experiments with deoxyribonucleic acid, using the Philpot-Svensson ${ }^{1}$ optical system, can be carried out at concentrations down to $5 \times 10^{-4} \mathrm{gm} . / \mathrm{ml}$. Although at this concentration only a slight spreading of the peak is observed ${ }^{2}$, this cannot be taken as an indication of the homogeneity of the material, since it is known from light-scattering measurements ${ }^{3}$ that interaction between the molecules only becomes small at concentrations less than $3 \times 10^{-5} \mathrm{gm} . / \mathrm{ml}$. The strong absorption in the ultraviolet shown by solutions of deoxyribonucleic acid can be used to measure the rate of sedimentation at concentrations down to $10^{-5} \mathrm{gm} . / \mathrm{ml}$. The results discussed in this communication refer to various dilutions of three different stock solutions prepared from one preparation (DNA7) ${ }^{4}$. 0.02-0.04 per cent of deoxyribonucleic acid was dissolved in water for twenty-four hours and then diluted with an equal volume of $0.4 M$ sodium chloride. These solutions 